\title{
ESTUDO SOBRE DOENÇAS SEXUALMENTE TRANSMISSfVEIS EM ESTUDANTES UNIVERSITÁRIOS
}

\author{
Silvio Augusto Margarido **
}

\section{NOTA PREVIA}

MARGARIDO, S. A. Estudo sobre doenças sexualmente transmissíveis em estudantes universitários. Nota prévia. Rev. Esc. Enf. USP, São Paulo, 14(2):201, 1980.

Embora não se tenham dados estatísticos reais sobre a incidência das doenças sexualmente transmissíveis no mundo, vários autores citam que, a partir da década de 50 , houve uma ascensão na incidência destas doenças, principalmente da sífilis e da blenorragia.

Assim como qualquer doença, a história natural das doenças sexualmente transmissíveis compreende as interrelações entre o agente etiológico, o hospedeiro e o meio ambiente.

Diante das mudanças ocorridas nestes fatores, alguns grupos estão mais expostos a contrair essas doenças. Segundo ANTAL et alii ${ }^{1}$ alguns grupos estão mais expostos pelas atividades que exercem, citando como exemplo os marinheiros, os trabalhadores separados de suas famílias, os turistas, os viajantes e outros, devido ao seu comportamento sexual, como ocorre com os jovens, os estudantes, os homossexuais e as prostitutas, grupos onde alguns indivíduos contraem denças venéreas repetidas vezes.

Autores como ARYA \& BENNETT ${ }^{2}$, WILLCOX ${ }^{3}$, em estudos realizados em alguns paises em desenvolvimento, na África e nas Américas, verificaram que cerca de 25 a $30 \%$ dos estudantes universitários se contagiam anualmente.

Frente a magnitude do problema das doenças sexualmente transmissíveis no mundo e, em particular em nosso meio, os profissionais de saúde pública sentem a necessidade de conhecer o problema na população e, em especial, nos grupos mais expostos, como os estudantes universitários.

O objetivo deste trabalho é, portanto, estudar alguns dados referentes ao comportamento sexual dos estudantes e o número de acidentes venéros ocorridos, a fim de subsidiar futuros programas de controle dessas doenças.

MARGARIDO, S. A. A study of sexual transmissible diseases in undergraduate students of an university in São Paulo. Previous note. Rev. Esc. Enf. USP, São Paulo, 14(2): $201,1980$.

This is a study about the sexual behaviour and venereal illnesses in undergraduate students of an university in São Paulo.

\section{REFERENCIAS BIBLIOGRAFICAS}

1. ANTAL, G. M. et alii. Aspectos sociales y sanitarios de las enfermedades de transmision sexual. Ginebra, OMS, 1977. 63 p. (Cuadernos de Salud Publica, n.॰ 65).

2. ARYA, O. P. \& BENNETT, F. (1967) apud GUTHE, T. Tendencias mundiales de la sifilis y la blenorragia. Bol. Ofic. sanit. panamer., Washington, 70(1): 6-25, 1971.

3. WILLCOX, R. R. (1967) apud GUTHE, T. Tendencias mundiales de la sifilis y la blenorragia. Bol. Ofic. sanit. panamer., Washington, 70(1): 6-25, 1971.

* Auxiliar de Ensino das disciplinas Enfermagem Preventiva e Comunitária e Saúde da Comunidade da EEUSP. 